\title{
Development of a mechanism that minimize the wear of ultralights tires
}

\author{
Alexandre Mateus Popiolek, Marcelo Hofmam da Silva, Pedro Correia Romio \\ Departamento de Engenharia Mecânica, Universidade do Vale do Itajaí - UNIVALI \\ e-mails: alexandreja_@edu.univali.br; mhofmam@univali.br; pedro.romio@univali.br
}

\begin{abstract}
The tire wear of the small aircraft landing gear is a critical factor in this technical system, with a direct impact on the maintenance costs of the landing gear, the maintenance of the landing track and the issues surrounding the fabrication of new tires. In this paper, the preliminary design of a mechanical device to be installed on the wheels of the landing gear is discussed, which aims to minimize tire wear, reduce the need to replace this item and improve the efficiency of the landing system. Through the application of a product development methodology (PRODIP Model), an equipment capable of overcoming the inertia of rotation and putting a wheel in motion before the tire contact with the landing track was designed. This new system uses an air mass movement system and does not require any other source of energy. The prototype has been developed already and it is in test stage, offering a general reduction of $89 \%$ in the tire consumption of the aircraft.
\end{abstract}

Keywords: design methodology, ultralights, tire wear, product development.

\section{Introduction}

Tire wear on small aircraft landing gear is a critical factor in this technical system, impacting maintenance costs, landing track maintenance and environmental issues surrounding tire production. Accumulation of rubber on the landing track is another important point of this effect that there is a specific frame to classify them as shown in Table 1 . When it reaches $80 \%$, landing becomes impractical with high risk of accidents (MESQUITA, 1993).

Agência Nacional de Aviação Civil (2016), defines that if exist an imbalance in the wheel, the heavier part will always tend to stay down by touching the ground first, resulting in severe wear at a single place on the tire, anticipating the replacement. Non-balancing also generates vibration, affecting the operation of the aircraft.

The present paper presents the development of a mechanism that aims to minimize the wear of ultralights tires. The stages of project development will be presented from a reference model (PRODIP Model) until the preliminary stage in the development of the prototype.

\section{Theoretical background}

Figure 1 shows the general view of the model used. The stages developed in this paper cover the Design Process, between the Informational Stage and Conceptual Stage.

Back et al. (2008), discusses the informational project as the first phase of product design. It is in this phase that we look for factors of influence in the project as requirements of customers and users. From the informational project is defined: influence factors in the manufacturing plan; strategy for supplier development; information on life cycle security; goals of dependability and target cost.

The conceptual design is treated by Back et al. (2008), as the development of product design. The global function and its sub functions are defined. Design selection considers: project specifications; target cost; development goals and safety and dependability quality goals.

\section{Research method}

The research method used in this project was the bibliographic study, and the practical tests with a model, that was used for data acquisition. First the aircraft model was chosen, assuming to be experimental, use for training, light, constructive simplicity, and equipped with tricycle type landing gear, using tires of the type $5.00-5$ Flight Special II, external diameter of 14,2 in.

It was necessary to choose the solution that best fits the user's needs. For this choice, was used the quality house (Table 2), which treat the requirements that users judge important for the construction of the device, versus the technical terms that allow them to measure such requirements. The user requirements were defined from an intuitive method called brainstorming session of the design thinking, performed in the hangars with the pilots, "recommended to find new solutions to more general problems, such as a new product, new solution principle [...]" (BACK et al., 2008, p. 253). 
Table 1. Rubber Accumulation Code for Landing Track.

\begin{tabular}{|c|c|c|}
\hline $\begin{array}{l}\text { Condition of the } \\
\text { pavement surface }\end{array}$ & $\begin{array}{l}\text { Alpha } \\
\text { Code }\end{array}$ & $\begin{array}{l}\text { Numeric code with } \\
\text { description }\end{array}$ \\
\hline \multirow{10}{*}{ Accumulation of rubber } & \multirow{10}{*}{ A } & 0 - Without accumulation \\
\hline & & $\begin{array}{l}1 \text { - Rubber covering } 10 \% \text { of } \\
\text { the texture }\end{array}$ \\
\hline & & $2-20 \%$ \\
\hline & & $3-30 \%$ \\
\hline & & $4-40 \%$ \\
\hline & & $5-50 \%$ \\
\hline & & $6-60 \%$ \\
\hline & & $7-70 \% *$ \\
\hline & & $8-80 \%$ \\
\hline & & $\begin{array}{c}9 \text { - Rubber covering } 100 \% \text { of } \\
\text { the texture }\end{array}$ \\
\hline
\end{tabular}

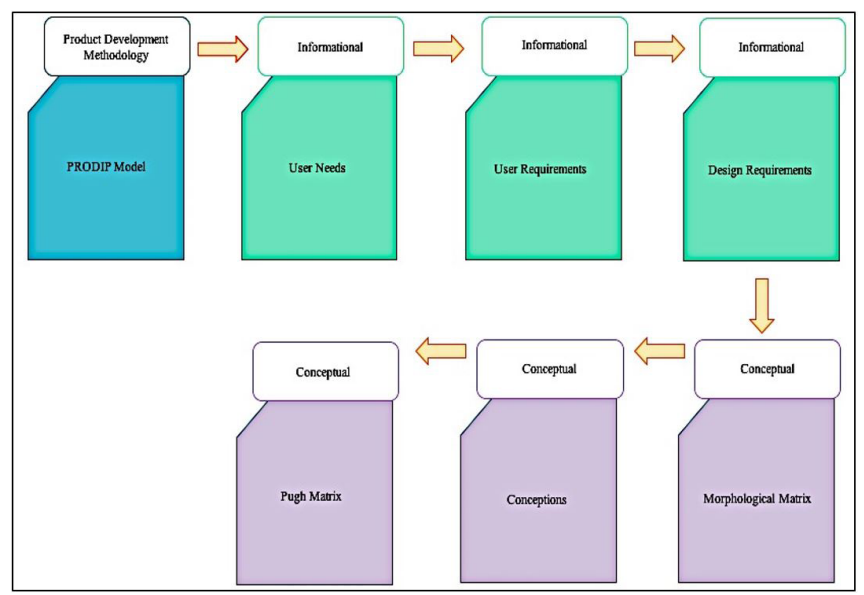

Figure 1. PRODIP Model Scheme applied to the project.

Table 2. Quality house.

\begin{tabular}{|c|c|c|c|c|c|c|c|c|c|c|c|c|c|c|c|c|c|c|}
\hline Project Requirements & & & & & & & & & & & & & & & & & 3 & \\
\hline User requirements & 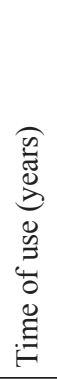 & 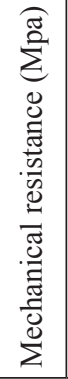 & 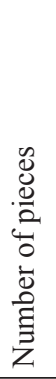 & 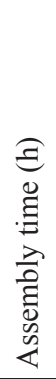 & 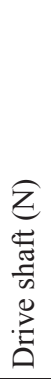 & 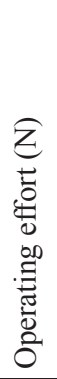 & 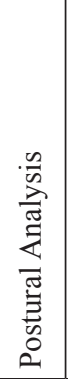 & 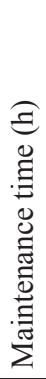 & 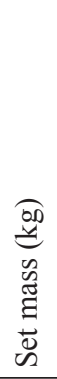 & 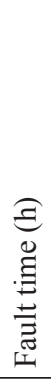 & 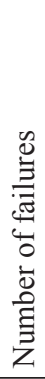 & 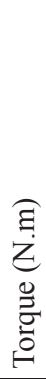 & 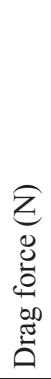 & 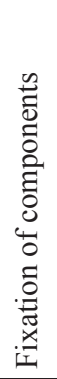 & 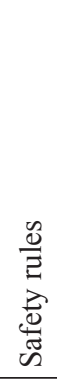 & 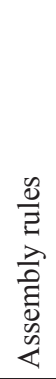 & 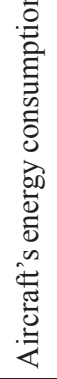 & 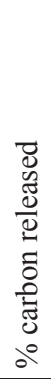 \\
\hline Durability & 5 & 5 & 1 & 0 & 3 & 1 & 0 & 1 & 0 & 5 & 5 & 3 & 3 & 3 & 0 & 0 & 0 & 0 \\
\hline Robustness & 3 & 5 & 5 & 0 & 3 & 1 & 0 & 1 & 3 & 3 & 3 & 3 & 5 & 5 & 1 & 0 & 1 & 0 \\
\hline Mounting & 1 & 0 & 5 & 5 & 0 & 0 & 5 & 5 & 1 & 5 & 5 & 0 & 0 & 5 & 3 & 5 & 1 & 0 \\
\hline Usability & 3 & 0 & 5 & 0 & 5 & 5 & 5 & 3 & 3 & 0 & 0 & 1 & 1 & 3 & 1 & 0 & 3 & 0 \\
\hline Ergonomics & 5 & 0 & 3 & 5 & 5 & 5 & 5 & 5 & 0 & 0 & 0 & 0 & 0 & 3 & 1 & 5 & 0 & 0 \\
\hline Maintainability & 5 & 5 & 5 & 0 & 0 & 0 & 5 & 5 & 3 & 5 & 5 & 0 & 0 & 5 & 5 & 5 & 0 & 0 \\
\hline Mass & 0 & 3 & 5 & 5 & 3 & 3 & 0 & 5 & 5 & 0 & 0 & 5 & 5 & 3 & 0 & 0 & 5 & 0 \\
\hline Reliability & 5 & 5 & 5 & 0 & 1 & 0 & 0 & 3 & 0 & 5 & 5 & 3 & 3 & 5 & 3 & 3 & 0 & 0 \\
\hline Functionality & 3 & 3 & 5 & 1 & 5 & 5 & 5 & 0 & 1 & 1 & 1 & 5 & 5 & 5 & 0 & 0 & 5 & 0 \\
\hline Drag force & 0 & 3 & 0 & 0 & 3 & 3 & 0 & 0 & 0 & 3 & 3 & 5 & 5 & 0 & 0 & 0 & 5 & 0 \\
\hline Safety & 3 & 5 & 3 & 1 & 0 & 1 & 0 & 3 & 3 & 5 & 5 & 1 & 1 & 5 & 5 & 5 & 0 & 0 \\
\hline Interchangeability & 1 & 0 & 5 & 5 & 0 & 0 & 0 & 3 & 0 & 3 & 3 & 0 & 0 & 5 & 0 & 5 & 0 & 1 \\
\hline Consumption & 5 & 0 & 0 & 0 & 5 & 0 & 0 & 0 & 5 & 0 & 0 & 5 & 5 & 0 & 0 & 0 & 5 & 3 \\
\hline $\mathrm{CO} 2$ emissions & 5 & 0 & 0 & 0 & 3 & 0 & 0 & 1 & 5 & 0 & 0 & 5 & 5 & 0 & 0 & 0 & 5 & 5 \\
\hline \multirow{2}{*}{ Prioritized design requirements } & 44 & 34 & 47 & 22 & 36 & 24 & 25 & 35 & 29 & 35 & 35 & 36 & 38 & 47 & 19 & 28 & 30 & 9 \\
\hline & $3^{\circ}$ & $10^{\circ}$ & $1^{\circ}$ & $16^{\circ}$ & $5^{\circ}$ & $15^{\circ}$ & $14^{\circ}$ & $7^{\circ}$ & $13^{\circ}$ & $8^{\circ}$ & $9^{\circ}$ & $6^{\circ}$ & $4^{\circ}$ & $2^{\circ}$ & $12^{\circ}$ & $17^{\circ}$ & $11^{\circ}$ & $18^{\circ}$ \\
\hline
\end{tabular}

The PRODIP Model was implanted generating in the conception stage an array of generic solutions (Table 3), in order to produce the conceptions array (Table 4).

The morphological matrix method consists a set of different combinations of elements or parameters, in order to find a new solution to the problem (BACK et al., 2008).

From the morphological matrix, it was possible generate ideas of mechanisms, which are presented in the Table 3.
For the generation of the conceptions was considered to resolve the design problem, that was to rotate the wheels of the landing gear to minimize tire wear. It was possible to generate 4 (four) solutions.

For the construction of the test model was chosen the concept 4 (four), through Pugh's matrix (Table 5). According Back et al. (2008), the Pugh matrix is a systematic screening by comparison. Recommended because it is simple and 
Table 3. Morphological matrix.

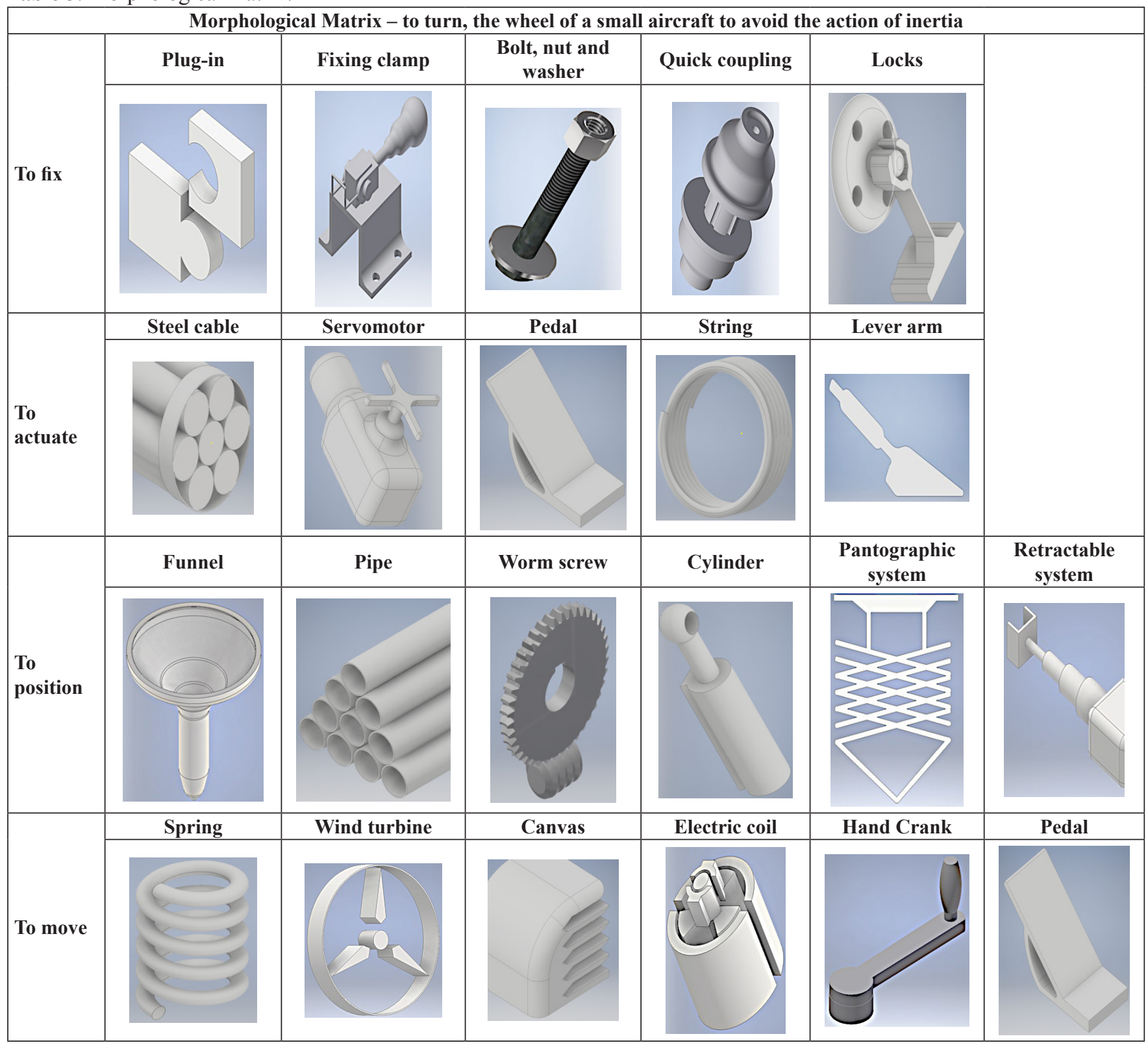

easy to apply, with the advantage of highlighting the best solutions and separating the viable from the unviable.

The concept was modeling on the 3D software. 3D drawings made possible preview the part before building. Figure 2 shows the isometric view of the model parts.

\section{Case study}

In order to check device performance regarding the consumption of tires, the prototype was tested following the steps shown in the Figure 3 that are: (a). the tire was weighed before the test with an electronic balance then landed 10 (ten) times with original system and (b). weighed again.
With this procedure, it was possible to know how much tire was worn, through the tire weight difference presented between the test steps.

The landings were repeated, but now using the mechanism to improve rotation to the wheel, now the ink used in the roll band, whose purpose was to show which parts of the tire suffered greater wear should be taken into account, because, however thin the layer, it changes the weight of the tire, compared to the previous test. It is possible to notice that the yellow ink belonging to the second part of the test added 3 grams (c). to the weight of the tire.

In the final part was compared the weights recorded, (b). and (d)., that generated the Table 6. 
Table 4. Matrix of conceptions.

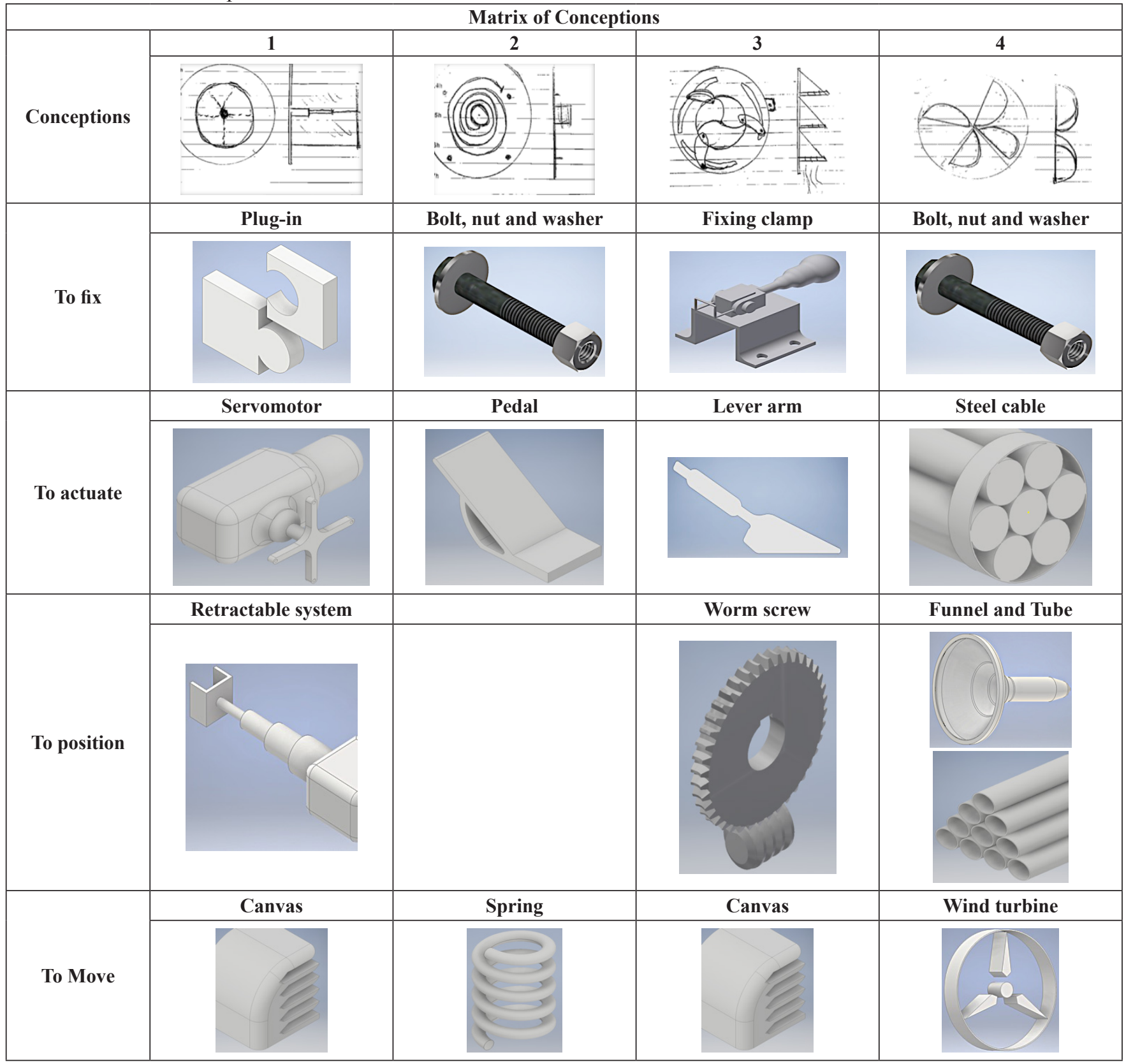

The tire wear shows according to Albertazzi (2008), a normal distribution (Gaussian), considering for this study a range of $1 \sigma$ (one sigma), equivalent to $68,27 \%$ of the rolling band, approximately $2 \mathrm{~g}$ (two grams) of the yellow ink were in the center of the tire band. The $1 \mathrm{~g}$ (one gram), at the end of the second test part, represents for the 10 (ten) landings using the device, that the tire did not receive significant wear of its contact band, thus evidencing the efficiency of the proposed device.
Performing a general wear analysis presented between steps (c). and (d), a reduction of approximately $89 \%$ can be perceived.

During all the landings and departures made, the procedures contained in the Brazilian aeronautical approval regulation number 103, subpart A (RBHA 103a) were followed.

The sample size was given by an average estimate, based on a standard deviation of 0.07746 , obtained by previous analyzes and with an expected error of $\pm 5 \%$. This data returns the value of 9.22 that has been rounded to 10 . 
Table 5. Pugh matrix.

\begin{tabular}{|l|c|c|c|c|}
\hline \multicolumn{5}{|c|}{ Pugh Matrix of Generated Conceptions } \\
\hline \multirow{2}{*}{ User Requirements } & \multicolumn{4}{c|}{ Solutions } \\
\cline { 2 - 5 } & Reference (4) & 1 & 2 & 3 \\
\hline Number of components & 0 & - & - & - \\
\hline Fixing of components & 0 & 0 & 0 & 0 \\
\hline Life cycle (years) & 0 & - & - & - \\
\hline Friction force (N) & 0 & 0 & 0 & 0 \\
\hline Drive force (N) & 0 & 0 & 0 & - \\
\hline Torque (N.m) & 0 & 0 & 0 & 0 \\
\hline Maintenance time (h) & 0 & - & - & - \\
\hline Time to failure (h) & 0 & - & - & - \\
\hline Number of failures & 0 & - & - & - \\
\hline Mechanical Resistance (Mpa) & 0 & - & 0 & + \\
\hline Power consumption $(\mathrm{W})$ & 0 & - & 0 & 0 \\
\hline Sum of $(+)$ & $0(+)$ & $0(+)$ & $0(+)$ & $1(+)$ \\
\hline Sum of $(-)$ & $0(-)$ & $7(-)$ & $5(-)$ & $6(-)$ \\
\hline Sum of $(0)$ & $11(0)$ & $4(0)$ & $6(0)$ & $4(0)$ \\
\hline Final result $(+)+(-)$ & 0 & $7(-)$ & $5(-)$ & $5(-)$ \\
\hline Placing & $1^{\circ}$ & $3^{\circ}$ & $2^{\circ}$ & $2^{\circ}$ \\
\hline
\end{tabular}

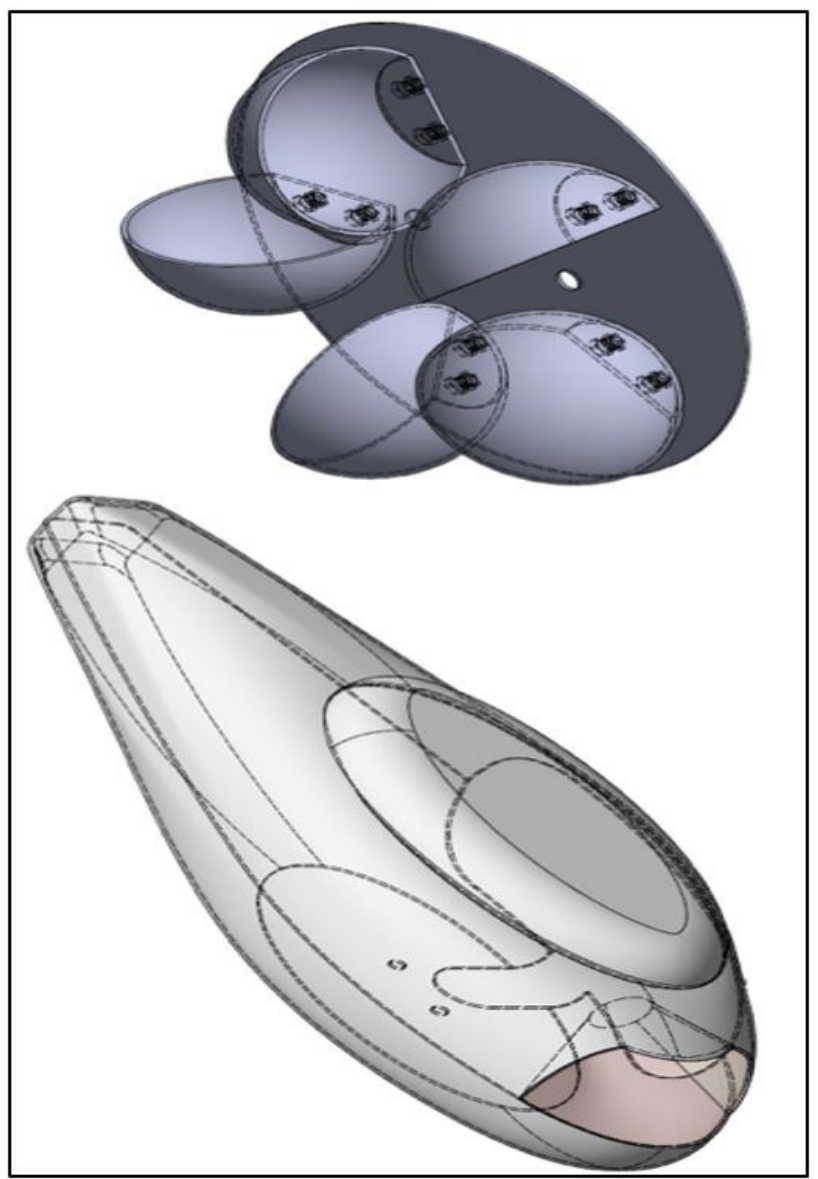

Figure 2. Model parts for test.
Table 6. Results of weights after testing the model.

\begin{tabular}{|c|c|c|c|}
\hline \multicolumn{4}{|c|}{ RESULT TABLE - TEST WITH MODEL } \\
\hline A & $\mathrm{B}$ & $\mathrm{C}$ & $\mathrm{D}$ \\
\hline $4329 \mathrm{~g}$ & $4320 \mathrm{~g}$ & $4323 \mathrm{~g}$ & $4322 \mathrm{~g}$ \\
\hline Difference A and B [g] & \multicolumn{2}{|c|}{1} \\
\hline \multicolumn{2}{|c|}{ Difference C and D [g] } & \multicolumn{2}{|c|}{} \\
\hline \multicolumn{3}{|c|}{ General percentage of economy presented: 89\% } \\
\hline A & Tire weight [g] \\
\hline B & Tire weight after landing without using the device [g] \\
\hline C & Tire weight + ink weight [g] \\
\hline D & Tire weight after landing using the device [g] \\
\hline
\end{tabular}

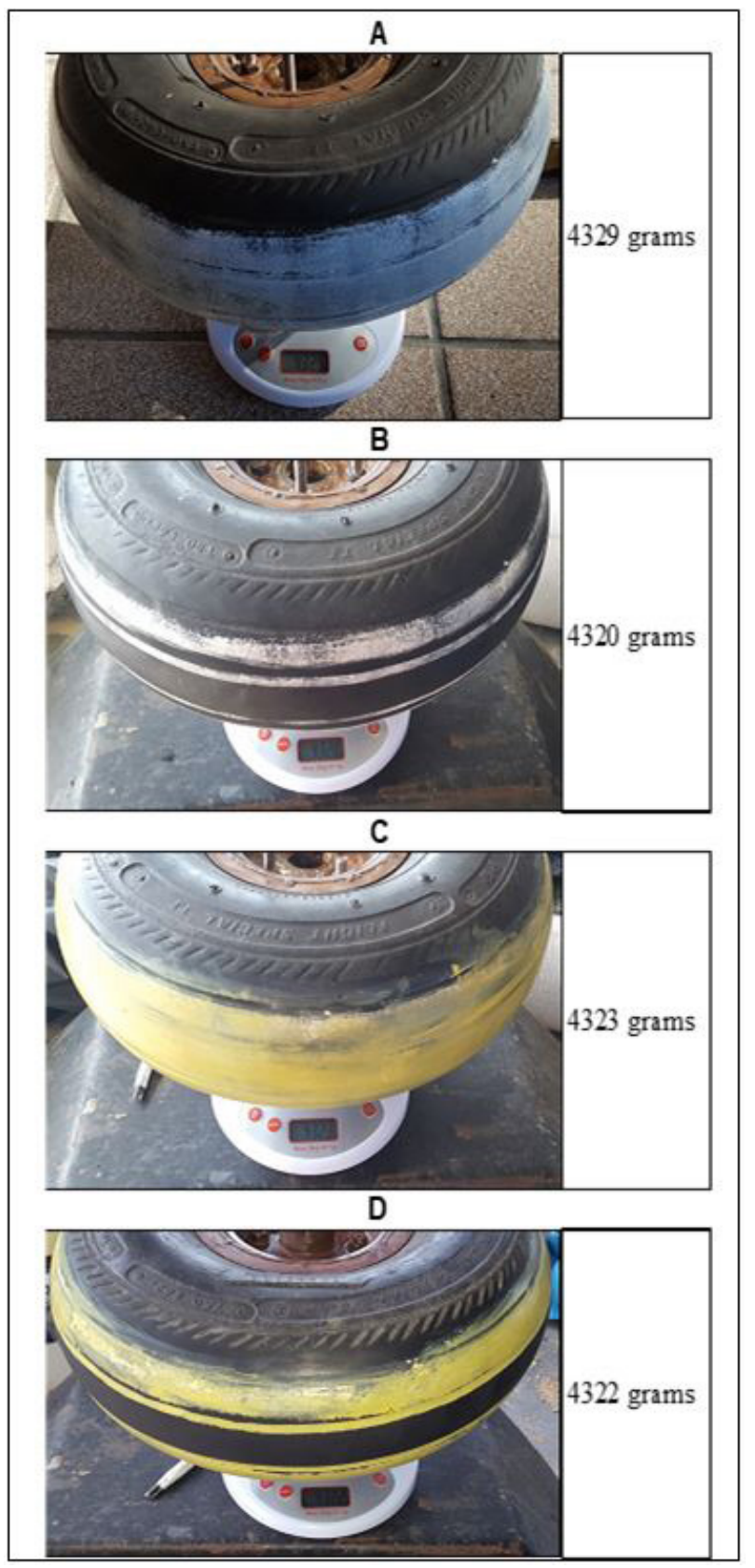

Figure 3. Steps taken to test the prototype. 


\section{Conclusions}

The adopted model, PRODIP Model, allowed the systematization of activities through a set of formal procedures where, from a general view, shows the importance of the stages for the development of the mechanism that allows to initiate the rotation of the wheel before contact with the landing track.

With the use of the mechanism, it was possible to reduce around $89 \%$ the wear of the scrolling bandwidth of the tires.

Also, the device contributed to a better and smooth landing, once there is no more a brake effect, because of the rubbing.

This work provides a foundation for future studies in the development of a more accurate measurement system for the wear of the tire rolling band, when it uses the device developed, and the influence of the product on the aircraft's fuel consumption, from when it is fired to the landing.

\section{References}

ALBERTAZZI, A. Fundamentos de metrologia: científica e industrial. Barueri: Manole, 2008.

AGÊNCIA NACIONAL DE AVIAÇÃO CIVIL. Apostila ANAC (celula): sistemas de trem de pouso. Brasília: ANAC, 2016.

BACK, N. et al. Projeto integrado de produtos: planejamento, concepção e modelagem. Barueri: Manole, 2008.

MESQUITA, F. M. F. Monitoração e melhoria das condições de atrito dos pavimentos. Reaer, 1993. Available from: $<$ http://reaer.org/index.php/reaer/article/view/48>. Access in: 4 March 2017. 